\title{
Dobutamine-induced Takotsubo syndrome during stress echocardiogram - An unusual but potentially severe association
}

Ditor Iglesias Mangolini²

(iD) Gabriel Bernardes Baron²

(iD) Guilherme Amaro'

(iD) Layara Lipari ${ }^{1}$

D Natalia Amstalden ${ }^{1}$

(iD) Rafael Tourinho Dantas ${ }^{1}$

(iD) Pedro Augusto Bastos ${ }^{1}$

Tatiana de Carvalho Andreucci Torres Leal,

(iD) Alexandre de Matos Soeiro,

1. Unidade Clínica de Emergência - InCor - HCFMUSP, São Paulo, SP, Brasil. 2. Liga de Emergências Cardiovasculares - InCor - HCFMUSP, São Paulo, SP, Brasil.

\section{INTRODUCTION}

Takotsubo syndrome is a clinical condition characterized by transient left ventricular apical dysfunction, associated with electrocardiographic alterations and increased markers of myocardial necrosis, in the absence of obstructive coronary lesion. This condition represents a differential diagnosis in patients with a scenario suggestive of acute coronary syndrome. Despite its association with situations of physical or emotional stress, there is very limited literature on the association of this condition with cardiac stress testing, methods widely employed in clinical practice. In this report, we describe a case of Takotsubo syndrome documented during an examination of stress echocardiography with dobutamine. ${ }^{1}$

\section{Case}

A 75-year-old female patient, undergoing outpatient follow-up due to atypical chest pain, was referred for stress echocardiography with dobutamine. She reported a history of hypertension, dyslipidemia, chronic kidney disease, obesity, and hyperthyroidism and made prior use of carvedilol $25 \mathrm{mg}$ /day, enalapril $5 \mathrm{mg} /$ day, and simvastatin $20 \mathrm{mg} /$ day.

During the resting echocardiogram, she showed preserved systolic function (56\% left ventricle ejection fraction), without changes in segmental mobility. After dobutamine $20 \mathrm{mcg} / \mathrm{kg} / \mathrm{min}$ and atropine $0.25 \mathrm{mg}$ infusion, she reached a heart rate of $148 \mathrm{bpm}$ (102\% of the maximum expected for her age). At peak stress, she 
began to report nausea and presented hypotension associated with left ventricular systolic dysfunction (ejection fraction estimated at 30\%), at the expense of apical akinesia, and hypokinesia of the other walls. An electrocardiogram showed ST-segment depression of the inferior wall, and the examination was interrupted (Figure 1). During the recovery stage, there was an improvement of symptoms with partial recovery of systolic function (40\% ejection fraction), but apical hypokinesia and a discreet ST-segment elevation in the inferior wall remained.

Thus, the patient was referred to the emergency department. At admission, she presented a blood pressure of $100 \times 50 \mathrm{mmHg}$, heart rate of $80 \mathrm{bpm}$, and respiratory and heart auscultation without changes. The electrocardiogram at admission in the emergency department showed no acute ischemic changes in the sinus rhythm. The markers of myocardial necrosis were positive with $1.19 \mathrm{ng} / \mathrm{mL}$ troponin I.

On the same day, the patient underwent cardiac catheterization, which showed coronary arteries without obstructive lesions, and ventriculography showing apical ballooning akinesis, with a diagnosis of the typical pattern of Takotsubo syndrome (Figure 2).

The patient was maintained on clinical therapy with carvedilol and enalapril and underwent cardiovascular

\section{FIGURE 1}

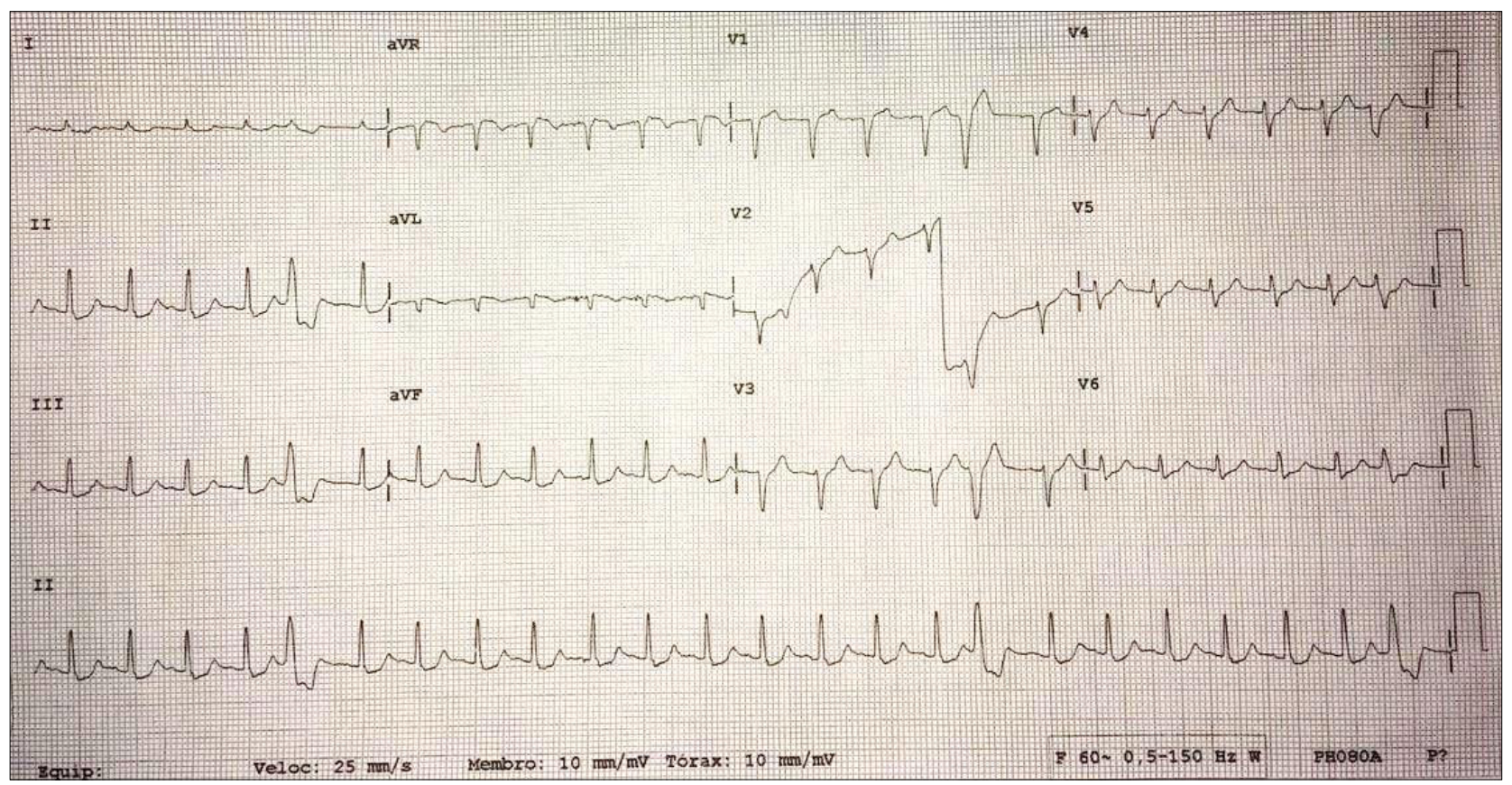

FIGURE 2

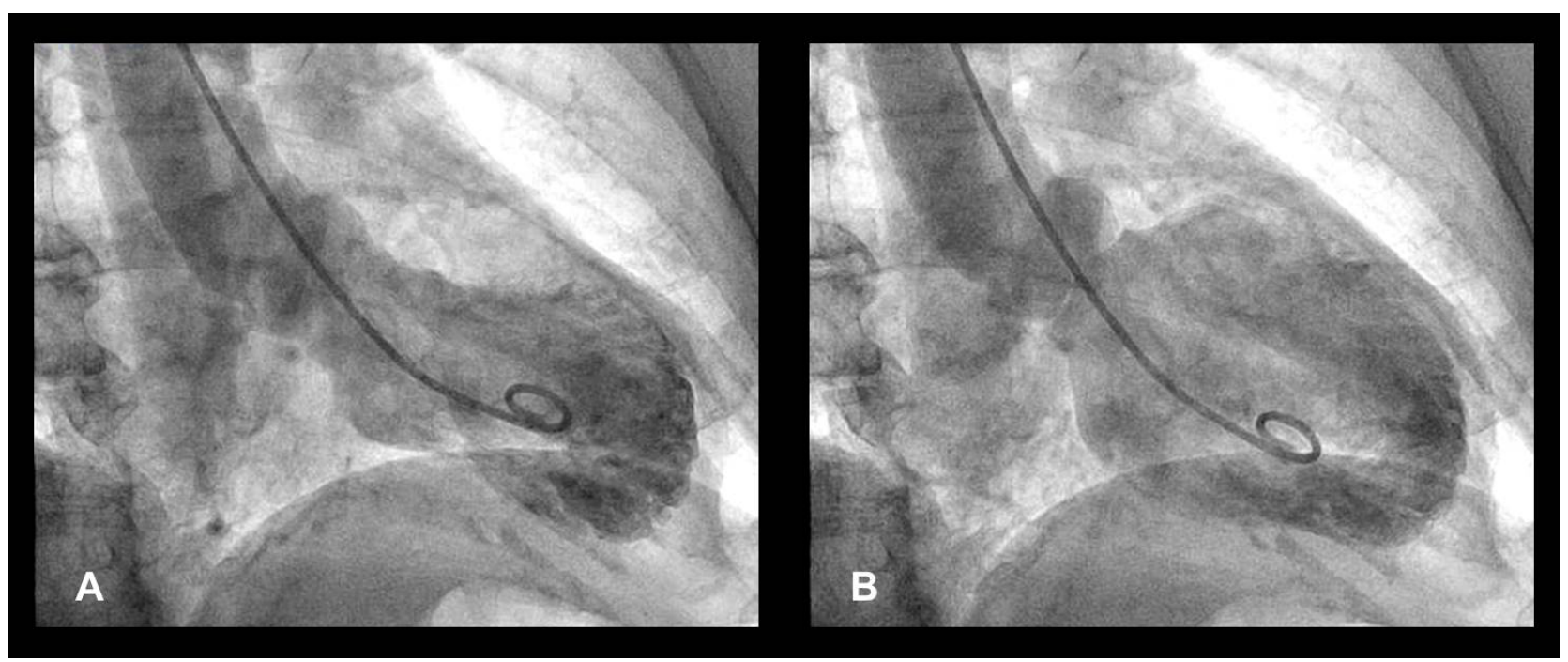


magnetic resonance, which showed a slightly reduced global systolic function of the left ventricle (46\% ejection fraction) at the expense of diffuse hypokinesia, more accentuated in the apical portion. The result corroborated previous examinations, demonstrating findings compatible with Takotsubo syndrome.

The patient progressed uneventfully and was discharged after 8 days of hospitalization.

\section{DISCUSSION}

Takotsubo Syndrome - also known as "broken heart syndrome" - was described for the first time around 1990 and is currently recognized as a differential diagnosis of chest pain. It is an unusual condition. Although its exact prevalence is not well established, it is estimated that it is responsible for about $2 \%$ of all cases treated as acute myocardial infarction with ST-segment elevation. ${ }^{1}$ This proportion rises to almost $6 \%$ when only women are studied. The estimated rate of recurrence of cases is around $1.8 \%$ per year. ${ }^{2}$

Its diagnosis is often challenging due to its clinical similarity with acute myocardial infarction, changes in electrocardiogram and biomarkers. Currently, cardiac catheterization with ventriculography is considered the gold-standard examination, along with the international diagnostic criteria for Takotsubo syndrome. ${ }^{3}$

Although its etiology is not fully known, there is evidence that it involves an intense sympathetic stimulation. Some of the proposed mechanisms by which the excess of catecholamines triggers the condition include: plaque rupture, epicardial vessel spasms, microcirculatory dysfunction, and direct toxicity in the cardiomyocytes. ${ }^{2}$ There is still no consensus regarding the treatment of Takotsubo syndrome, in both its acute or long-term presentation. Despite this, the evolution of the Takotsubo syndrome tends to be benign, with ventricular dysfunction being solved over a period of days or weeks. ${ }^{4}$

However, the description of the syndrome after stress echocardiography with dobutamine is unusual.

In 2008, Silberbauer et al. ${ }^{5}$ described one of the first cases of a 75-year-old woman who presented
Takotusubo syndrome during stress echocardiography with dobutamine. The patient presented ST-segment elevation and received antithrombotic medication before cardiac catheterization. She had full recovery of ventricular function during clinical follow-up. ${ }^{5}$ Similarly, another case reported in 2009 by Margey et al. ${ }^{6}$, also in a woman, occurred during dobutamine infusion, and the left ventricle ejection fraction was fully recovered in 72 hours.

In Brasil, there is only one case, reported in 2009, associated with stress echocardiography in a 76-yearold patient who presented the condition during the infusion of the medication, showing an elevation of the sidewall all and taking 21 days to fully recover ventricular motility. ${ }^{7}$

In 2011, there was the first description of a case of Takotsubo syndrome related to the infusion of dobutamine in stress echocardiogram during the recovery stage in a 85-year-old patient. Back then, the authors called attention to the possibility of the condition happening not only at peak effort but also during the recovery from the exam. ${ }^{8}$

A survey of 22 cases of dobutamine-induced Takotsubo syndrome in imaging exams found that most reports were in females $(86 \%)$, with a mean age of 65 years $^{9}$. The most frequent clinical presentations were chest pain (56\%), followed by asymptomatic patients. A dobutamine dose of $30-40 \mathrm{mcg} / \mathrm{kg} / \mathrm{min}$ was involved in a greater number of the reported cases $(n=16)$ compared with lower doses. In addition, in 6 of these cases, the syndrome occurred during the period of recovery from the stress test. In the vast majority of cases, the evolution was benign (90\%), although one death was reported in the 22 documented patients. ${ }^{9}$

\section{CONCLUSION}

Takotusubo syndrome can be triggered by pharmacological stress and is mainly associated with dobutamine. Although rare, its risk should not be overlooked in exams with pharmacological adrenergic stress, and the indication for these exams should involve caution and knowledge of its complications. 


\section{REFERENCES}

1. Prasad A, Dangas G, Srinivasan M, Yu J, Gersh BJ, Mehran R, et al. Incidence and angiographic characteristics of patients with apical ballooning syndrome (Takotsubo/stress cardiomyopathy) in the HORIZONS-AMI trial: an analysis from a multicenter, international study of ST-elevation myocardial infarction. Catheter Cardiovasc Interv. 2014;83(3):343-8.

2. Templin C, Ghadri JR, Diekmann |, Napp LC, Bataiosu DR, Jaguszewski M, et al. Clinical features and outcomes of Takotsubo (Stress) cardiomyopathy. N Engl ) Med. 2015;373(10):929-38.

3. Ghadri JR, Wittstein IS, Prasad A, Sharkey S, Dote K, Akashi YJ, et al. International expert consensus document on Takotsubo syndrome (Part I): clinical characteristics, diagnostic criteria, and pathophysiology. Eur Heart I. 2018;39(22):2032-46.

4. Redfors $B$, Vedad R, Angerås $O$, Råmunddal T, Petursson $P$, Haraldsson I, et al. Mortality in Takotsubo syndrome is similar to mortality in myocardial infarction: a report from the SWEDEHEART registry. Int J Cardiol. 2015;185:282-9.
5. Silberbauer ), Hong P, Lloyd GW. Takotsubo cardiomyopathy (left ventricular ballooning syndrome) induced during dobutamine stress echocardiography. Eur | Echocardiogr. 2008;9(1):136-8.

6. Margey R, Diamond P, McCann H, Sugrue D. Dobutamine stress echo-induced apical ballooning (Takotsubo) syndrome. Eur J Echocardiogr. 2009;10(3):395-9.

7. Vasconcelos Filho Fl, Gomes CA, Queiroz OA, Barreto |E. Dobutamine stress echocardiography-induced broken heart syndrome (Takotsubo Syndrome). Arq Bras Cardiol. 2009;93(1):e5-7.

8. Shah BN, Simpson IA, Rakhit D). Takotsubo (apical ballooning) syndrome in the recovery period following dobutamine stress echocardiography: a first report. Eur J Echocardiogr. 2011;12(1):E5.

9. Hajsadeghi S, Rahbar MH, Iranpour A, Salehi A, Asadi O, Jafarian SR. Dobutamine-induced Takotsubo cardiomyopathy: a systematic review of the literature and case report. Anatol J Cardiol. 2018;19(6):412-6. 